\title{
Design and Implementation of Solar Tracker to Defeat Energy Crisis in Pakistan
}

\author{
Qamar Atta Ul Haq
}

Computer Science Department, ISP University 9-KM Bosan Roads, Multan Pakistan

Received: 18 December 2018; Accepted: 15 February 2019; Published: 08 March 2019

\begin{abstract}
Proposed Solar tracker minimizing the angle of incidence and solar panel position towards the sun to achieve the maximum solar irradiation and strength so that it can produced the maximum output (electricity).

Index Terms: Solar energy, photovoltaic (PV), Solar tracker, Solar city, Solar power, Concentrating solar power (CSP), Solar tacking, Two axis tracker, LDR (Light Dependent Resistor), Sensors, Servomotor, AVR microcontroller, Arduino Mega 2560.
\end{abstract}

(C) 2019 Published by MECS Publisher. Selection and/or peer review under responsibility of the Research Association of Modern Education and Computer Science.

\section{Introduction}

In May 2003 established the AEDB (Alternative Energy Development Board) with the intention of providing the facilitation, encouraging and promoting the ARES (Alternative Renewable Energies) development. In 2006 Ministry of water and the power take charge the AEDB with the task to generate the 5\% power of the total NPP (Nation Power Production) so that the country providing the facilitation to the approximate the $\mathbf{7 8 7 5}$ villages that facing the 20 hours of load shedding under the control and observation of the World Bank founded organization ESMAP (Energy Sector Management Assistance Program). [3]

Solar energy in Pakistan converses the generation and maturation of electricity by means of the solar thermal and photovoltaic technology. The eight to nine hours of the sunshine of sun per day in the Pakistan climatic situation are the ideal to generate the electricity with the help of solar energy. Pakistan solar potentials as well PV (photovoltaic) chances is about $\mathbf{2 . 9}$ million megawatts. Pakistan takes the initially steps to build the power plants that are grounded the renewable resources instead of using the fuel that causes the global warming and many more diseases. KPK (Khyber Pakhtunkhwa), Sindh, Baluchistan, Kashmir is the provinces that adopting

\footnotetext{
* Corresponding author. Tel: +92-61-111-786-477

E-mail address: qamarattaulhaq@gmail.com
} 
the solar technology based electricity but Now the Punjab under the Chief Minister of Punjab Shabazz Sharif is trying to developing the power plant infrastructure that produces the electricity with the use of LNG (Liquefied natural gas), Natural gas, Coal and Thermal based electricity, which produced the pollutants that causes the air and land pollution and annually $\mathbf{2 2 7 0 0}$ deaths occur in Pakistan due to the unhealthy environment. My work is about to atomize the solar system is a little struggle and contribution to attain and achieve the public intention and give awareness about using the solar energy so that we should have to minimize the use of unrenewable resources and made self-electricity generation system. [3]

The fact of global warming increase the demand to reduce the use of fuel base and other sources of energy that's generates or produced the heat, to avoid this factor and global warming, we should have to use the energy generation sources that produce minimum heat or the alternative source of energy that replace the fuel. Solar energy is the best way to utilize the sunlight to generate the power in the form of electricity. Our purpose to gain maximum strength of the sun rays that falls on the solar panel by adjusting the solar panel position. It is done by LDR (Light Dependent Resistor) and the audio chip that is controlled and manage from the Arduino programs that possess the instruction to automate the or rotate the solar panel that is attached to LDR and the moving function of the device performed by the motors. In this way we can achieve the maximum of sunlight in the generation of electricity so that we can light up the home, colony, streets, state and the world. [17]

This is the solar tracking system which can be employed for very efficient power Generating method from the sunlight. This method of a power generation is Simple required and needs only the sunlight to generate a power. This system serves to power Generation by adjusting the equipment to acquire maximum sunlight automatically, so that we can acquire maximum power as output. This system tracks the maximum intensity and strength of light. In case of diminution in the Intensity of light, this system automatically varies its direction to acquire Maximum intensity and strength of light. I'm utilizing a combination of LDRs (Light Dependent Resistors) output to gumption mean sense the maximum intensity and vividness of Light. The highest outturns outputs of LDRs (Light Dependent Resistors) of the combination that determine and decide the Rotation of the solar panel with the help of motors. I'm also employing the Arduino microcontroller as for tracking sunlight strength. It will be process the input obtained from the LDRs (Light Dependent Resistors) and assure the direction, so that the motor has to be revolved and it will obtain the Maximum intensity and strength of light coming from the sun. Our mission and aim of this research is to provide the solution of load shedding. [17]

Solar energy pertains primarily to the employ of the solar irradiation for pragmatic ends. Solar engineering are broadly characterized and qualified as either passive or the active depending on the direction they capture and convert spread sunlight. Active Solar engineering employ PV (photovoltaic) panels to convert the Sunlight into utilitarian outputs. Passive solar engineering includes the selection of Materials with prosperous thermal properties, designing and the contriving spaces that acquire the naturally Circulate air and citing mean referencing the position (perspective) from a building to the Sun [3]

Active Solar technologies enhances the render (supply) of energy and considered supply Side technologies, In other hands the passive solar technologies decrease the demand (need) for Alternate resources, generally considered demand (requirement) side technologies. Solar tracking system will serve us to utilize the every second of solar energy in efficient and more effective way so that our system lie (prevarication) in active technology. [3]

\section{Literature Rview}

The Robert H. Dold is the person who describe and depict the axis solar tracking system in 2007.Later on the Ronal P Corioc he introduced to link all of the solar panels in mechanically in array in 2008. William Taylor firstly introduced the first moveable solar tracker in 2009.Nader Barsoum in 2010 and Tiberiu Tudorache in 2012 proves that singles axis tracking system can be $22 \%$ efficient in its power production. Okpeki describe in practically bi directional solar system in 2013. However more than 15 country contribute in transforming technology in renewable resources as a type of solar energy, for that purpose dual axis solar tracking system 
introduced so that we can utilize all of the day solar irradiations coming from the sun. My contributions is to enhance the productivity and efficiency of solar tracker from $59 \%$ to $65 \%$ by the use of $5^{\text {th }}$ LDRs and addition codding algorithm. The energy that a sun produce and enter in the earth atmosphere can be calculated by the following law of Stefan and Boltzmann

$$
p=4 \pi \mathrm{r}^{2} \sigma \varepsilon \mathrm{T}^{4} \mathrm{~W}
$$

$\mathrm{T}$ is the temperature constant which value is $5800 \mathrm{k}$ and assumption that a radius of the sun $\mathrm{r}=695800 \mathrm{~km} . \sigma$ which is the Boltzmann constant $\sigma=1.3806488 \times 10^{-23} \mathrm{~m}^{2} \mathrm{~kg} \mathrm{~s}^{-2} \mathrm{~K}^{-1}$

And $\varepsilon$ is the emissivity of sun surface. The sun solar irradiation per year that enters in the earth atmosphere is about $5.10^{24}$

Joules which is 10000 times greater from the total energy consumption of the earth worldwide in one year. Luminous flux means LUX which unit is the lumen is the amount of light or energy that a solid angle steradian produce in one second from the single candela.

$$
1 \mathrm{~lx}=1 \mathrm{~lm} \cdot \mathrm{m}^{-2}=1 \mathrm{~cd} . \mathrm{sr} \cdot \mathrm{m}^{-2}
$$

Table 1. Brightness Range of Sunlight

\begin{tabular}{|l|l|}
\hline Time of day & Luminous flux (lux) \\
\hline Sunrise or sunset on a clear day & 400 \\
\hline Overcast day & 1000 \\
\hline Full day (not direct sun) & $10000-25000$ \\
\hline Direct sunlight & $32000-130000$ \\
\hline
\end{tabular}

\section{Method and Model}

Our proposed model is to minimize the wastage of solar irradiations strength by maintaining the solar panel 90 degree angle with the sun, for that purpose I take 5 LDRs sensors. Four LDRs is placed in each corner of solar panel frame and one in the middle, now my method is to compare the average of 5 LDRS with each other. Suppose Four LDRS is right=LDR1, Centre=LDR2, left=LRD3, up=LDR4, down=LDR5, then from calculating the average and from comparisons of LDRs values we can adjust the solar panel frame horizontal and vertical positions in a 360 degree. I can adjust the horizontal position of the frame by algorithm If (right $>$ Centre $\& \&$ left $<$ Centre) and if (left $>$ Centre $\& \&$ right $<$ Centre), if (up > Centre $\& \&$ down $<$ Centre) and from if (down $>$ Centre \&\& up < Centre) we control the adjustment of vertical position of the solar panel frame.

\section{Solar Measurement Stations in Pakistan}

1. QA (Quaid I Azam) solar park BWP (Bahawalpur).

2. NUST Islamabad (National University of Science and Technology)

3. KSK (Kala Shah Kaku) UET Lahore campus.

4. MNS (Muhammad Nawaz Sharif University) UET Lahore campus.

5. UET (University Of engineering and technology Peshawar).

6. NED (University of Engineering and Technology SINDH Karachi).

7. Jamshoro MUET (Mehran University of Engineering and Technology).

8. BUITEMS (Baluchistan University of Information Technology Quetta).

9. BUET (Baluchistan University of Engineering and Technology Khuzdar). [4] 


\section{Solar Energy Application}

The applications of the solar energy in order to defeat the situation and the problem of the Load shedding in Pakistan is following [2]

1. SSL (Solar Street Lighting) is placed in the solar system that save approximate the 300MW (Mega Watt) which is the annual electricity consumption in the street lighting purposes of Pakistan.

2. Putting the BBL (Bill Board Lighting) on the solar system that annually save and preserve approximate the 5MW (Mega Watt).

3. SWP (Solar Water Pumping) that is the most important because the Pakistan is a country who generates its revenue $80 \%$ from the agriculture areas and that requires the more and more power for irrigation and agriculture areas that save approximate the 1000MW (Mega Watt) by providing the facility of solar system to the farmers of Pakistan. [3]

4. Ruler development (Electrification) which name is RPP (Roshan Pakistan Program) that facilitate the approximate the 8000 villages that save the 25MW (Mega Watt). [3]

5. The use of the Solar Water Heaters that save the consumption of the natural gas which is about the 146600 TOE. [3]

6. The Government of Pakistan introducing the small level power projects that limit is One MW (Mega Watt) which license is free mean no taxes and other payments are to be paid to the Governments of Pakistan which is the big step by the Governments of Pakistan in order to defeat the Load Shedding. [3]

Table 2. Electronic Usage Efficiency [15]

\begin{tabular}{|c|c|c|c|c|}
\hline KVA & Watts & Battery & Appliances & Price \\
\hline $1 \mathrm{KVA}$ & 1000 & 1 wet, $200 \mathrm{amp}$ & $\begin{array}{l}\text { 1.one laptop/TV } \\
\text { 2.four fans } \\
\text { 3.Eight energy savers }\end{array}$ & $9480 /-$ \\
\hline $2 \mathrm{KVA}$ & 2000 & 2 wet, $200 \mathrm{amp}$ & $\begin{array}{l}\text { 1.one computer } \\
\text { 2.oneTV } \\
\text { 2.Six fans } \\
\text { 3.Ten energy savers }\end{array}$ & $14600 /-$ \\
\hline $3 \mathrm{KVA}$ & 3000 & 2 dry,200amp & $\begin{array}{l}\text { 1.one computer } \\
\text { 2. one TV } \\
\text { 2.Ten fans } \\
\text { 3.Twelve energy savers } \\
\text { 4.one refrigerator }\end{array}$ & $27500 /-$ \\
\hline $4 \mathrm{KVA}$ & 4000 & 4 dry,200amp & $\begin{array}{l}\text { 1.one computer } \\
\text { 2. one TV } \\
\text { 2.Ten fans } \\
\text { 3.Twelve energy savers } \\
\text { 4.one refrigerator } \\
\text { 5.one ton AC }\end{array}$ & $30000 /-$ \\
\hline $5 \mathrm{KVA}$ & 5000 & 6 dry,200amp & $\begin{array}{l}\text { 1.two computers } \\
\text { 2. two TV } \\
\text { 2.Ten fans } \\
\text { 3.Twelve energy savers } \\
\text { 4.one refrigerator } \\
\text { 5. one ton AC }\end{array}$ & $34700 /-$ \\
\hline
\end{tabular}

\section{Price Configuration And Solar System}

The price of the 300watt (mono crystal solar panel) is Rs 19000/-, 150 watt is Rs 9000/-, 100 watt is Rs 
6000/- and the Narda PGB (Polymer Gel Battery) Rs 36000/- which is very high price than normal battery and support long time. The cost of the invert and the gel battery is highest calculated as for required for the 5000 watts. [2]

\section{Existing and the Current System}

The existing solar system is also called the manual system in which panel works manually after the installation of solar panel, no rotation assume ascribable (due) to the fixed and fastened adroitness which means installation of the solar panels. The recent installation of the solar panels in fixed position is the Quaid I Azam solar park power station in BWP (Bahawalpur) [19]. The solar park is divided into III phases in area of the 6500 acres, phase I of power 100MW is completed in 2015 of cost $\$ 150$ million Dollars and phase II is in the process of commissioning that have the power of generation electricity is about 300MW and the phase is planned after the compilation of the first and the second phase. Phase III have approximate the planned 600MW power of generating the electricity. The Quaid I Azam solar park have the signed and the planed capacity of power generation in 2015-2016 (160083000 kWh) to 2017-2018 (160568000) due to the Flat Panel photovoltaic installation that means we are not adopting the new technologies so that the generating power is decreases power of the total power production due to the $39 \%$ wastage of the solar irradiation It is waste of the solar irradiation that we are using to generate the power as in the form of electricity. [19]

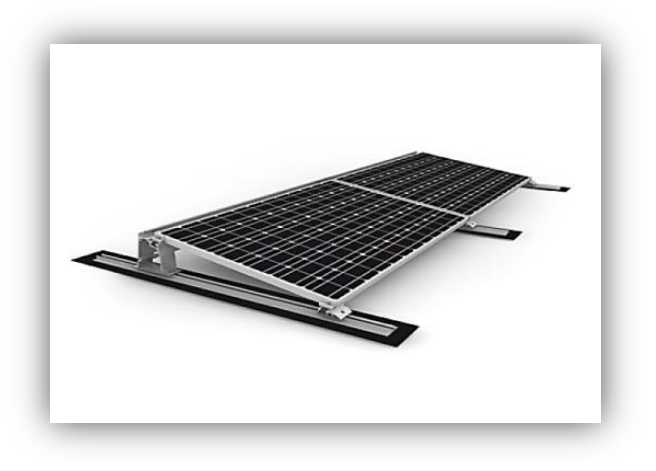

Fig.1. Flat Panels [12]

\section{Proposed System}

Dual axis tracking system in which the solar panels are fixed in the metal frame which is hang with the help of the rod or any other so it can leant and tilted in two direction toward the sun to get the maximum strength of solar irradiations.

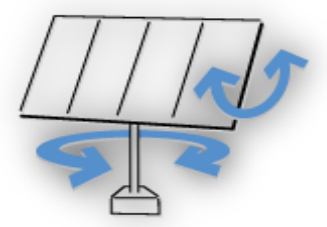

Fig.2. Dual Axis [12] 


\section{Design and Circuit Diagram}

The algorithm is works on the basics of the comparison of LDRs (Light Dependent Resisters) values. Four LDRs is placed near to the every and each corner of the solar panel, solar irradiation falls on the LDRs then the LDRs measures the solar irradiations that is coming from the sun. Then our algorithm is about to work on the comparison method of LDRs values, then our program that we code is now in working and compare the pairs of LDRs values, Which pair of LDRs values is greater than the motor will move towards that side where the solar irradiation strength is greater than the other LDRs. No matter whether the values of LDRs is high in upper and lower position or direction because the solar tracking system will move in both or dual directions to gain the maximum input as in the form of solar irradiations and generate the maximum (as output called yield, as our aim) of electricity. The diagram of the algorithm is given below which have the approximate the 5 steps as algorithms not in the coding or in the hardware it is separate issue and compels issue. [9]

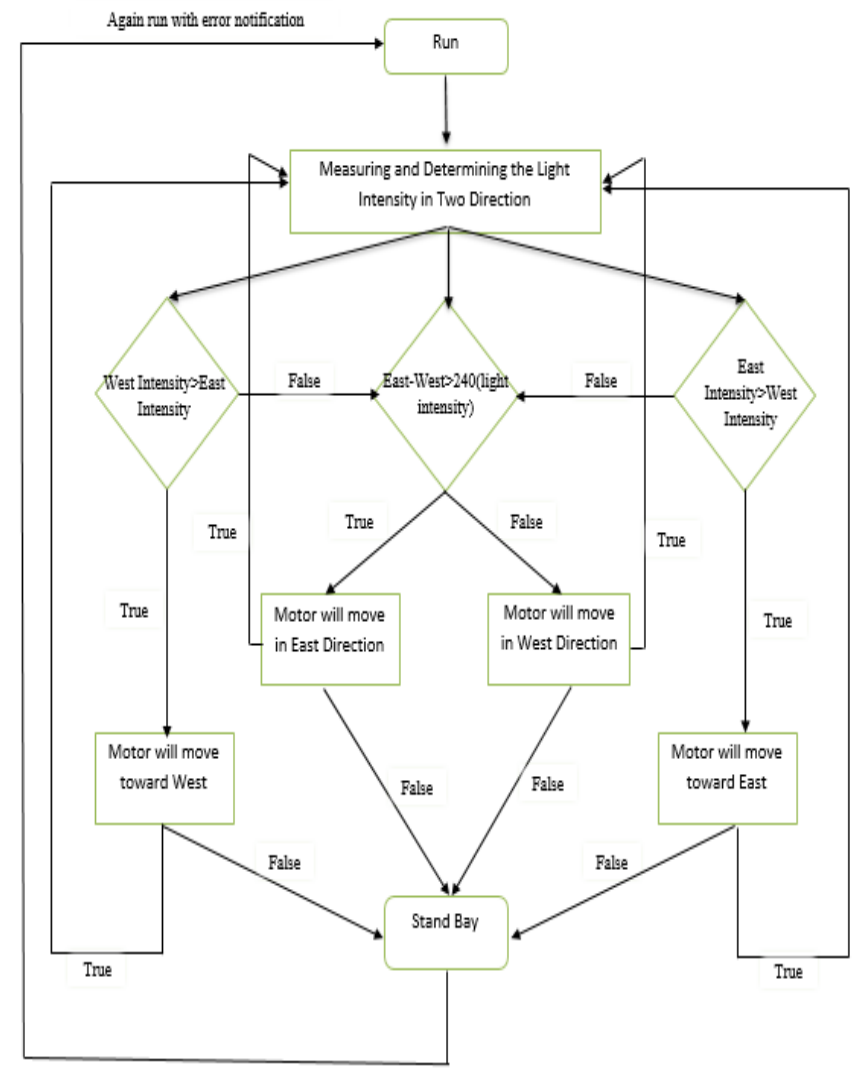

Fig.3. Data Flow Diagram and decision Tree [7, 8, 21, 26]

Circuit diagram of the solar tracking system is following and the parts are also mentioned in the circuit. The circuit works as the sun light falls on the solar panel as well as sun light falls on LDRs (Light Dependent Resisters) is usually four in strength which is present at the end of the four solar panel corner, the strength of the LDRs is decreases or increases depend of the developer's selection and choice. Then our code which is present in the Arduino Mega 2560 .We use the average values of four LDRs so that we will able to rotate the motor which will be in the result of the average values of LDRs.[17] 
If the average values of West intensity is greater than the east intensity than the motor will move towards the West and then return back to the detection mode or starting point, if the motor will not rotate due to some error then we start from the initial point rather than of insisting to rotate the motor any cost. We do same like this for four LDRs average values and same activities but different average values locations that results from the four corners of the solar panel like East, West, East-West $>=240$ (Light Intensity) average values. Then our code make decision for motor rotations. Daylight $=5000 \Omega$ and Dark=20000000 $\Omega$. [17]

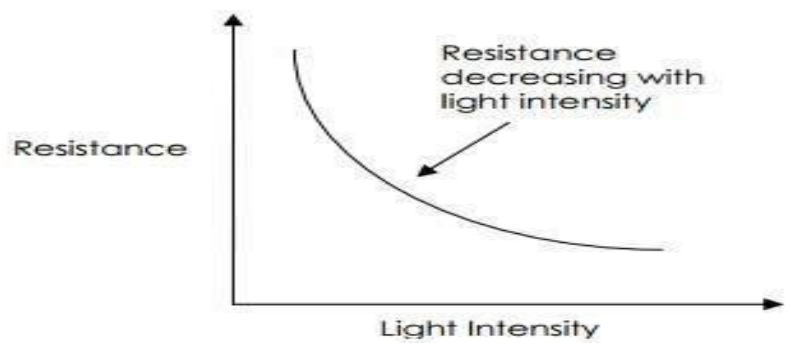

Fig.4. LDRs Graph [17, 18]

\section{Mathematical Modeling}

Where $\mathrm{n}$ is the representing the delay, $\delta$ called delta which represents the angle, $h$ representing the altitude of the solar tracker angle, $\gamma$ represents the azimuth which is $\gamma=0.527721566 \ldots$, $\varphi$ which is the geographical altitude and $t$ is the sun angle in the hour[27]

$$
\begin{aligned}
& \delta=23.45 \times \sin \left[2 \pi \times \frac{(284+n)}{365}\right] \\
& \sin (h)=\sin (\varphi) \sin (\delta)+\cos (\varphi) \cos (\delta) \cos (t) \\
& \sin (\gamma)=\cos (\delta) \sin (t) / \cos (h)
\end{aligned}
$$

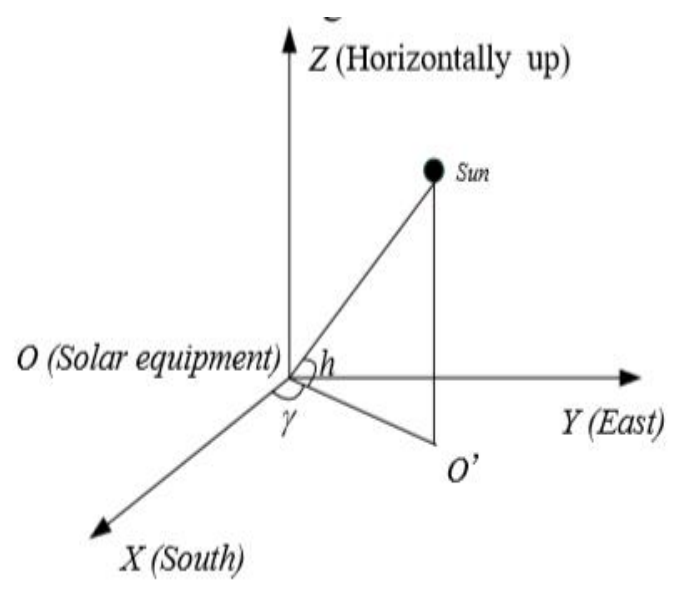

Fig.5. Solar Tracking Coordinate System [27] 


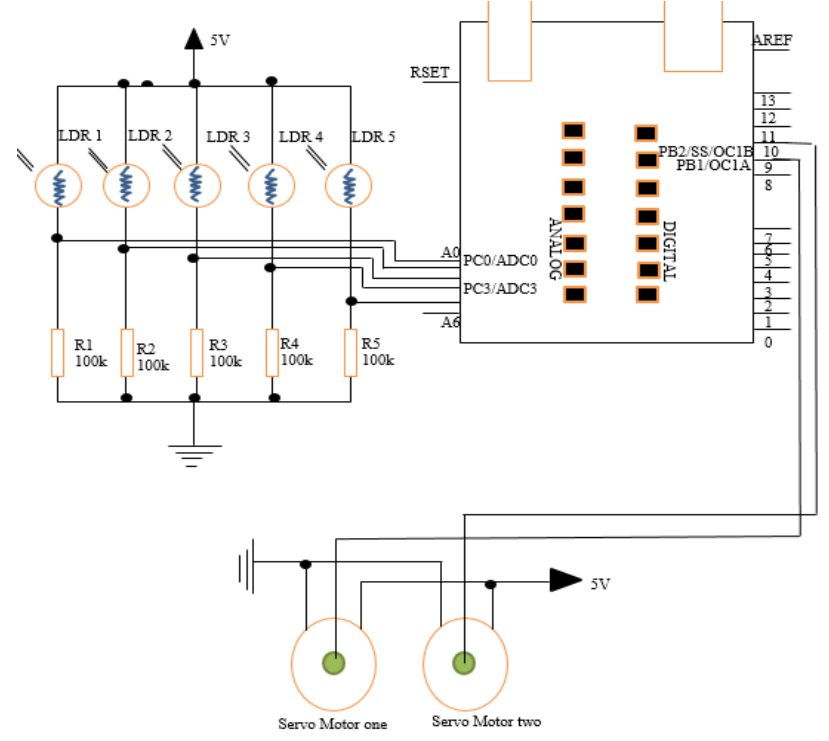

Fig.6. Circuit Diagram $[1,9,18]$

In the design of the circuit which is above shown I am using the five LDRs for the sake to increase the efficiency of the project to achieve the maximum strength of solar irradiations. The purpose of using fifth LDRs is to improve sensor link that's works to obtains light strength in the form of signals which is then transfer to Arduino board to process the output of LDRs which is in the form of analog signals (processing is done by the processor and processor work according to our instructions or codding that we write in Arduino language which is the $\mathrm{c}$ and $\mathrm{C}++$ combination based languages. [26]

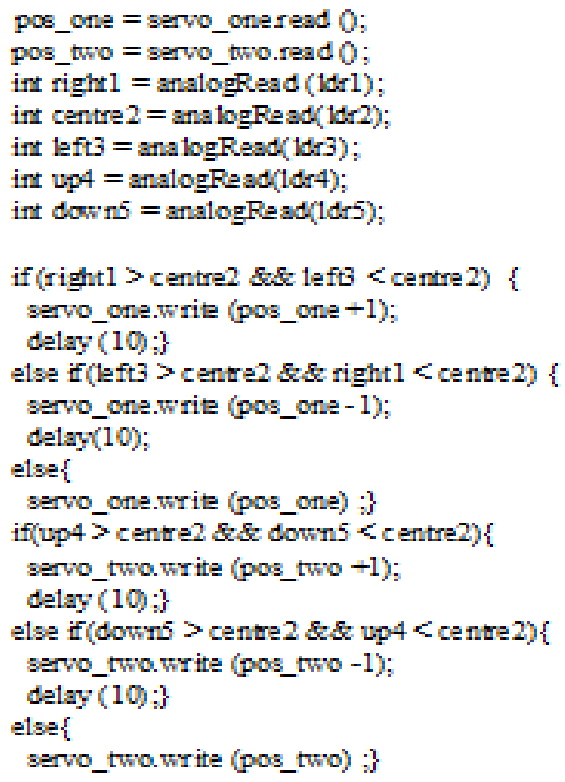

Fig.7. Algorithm and Code for Micro Controller 


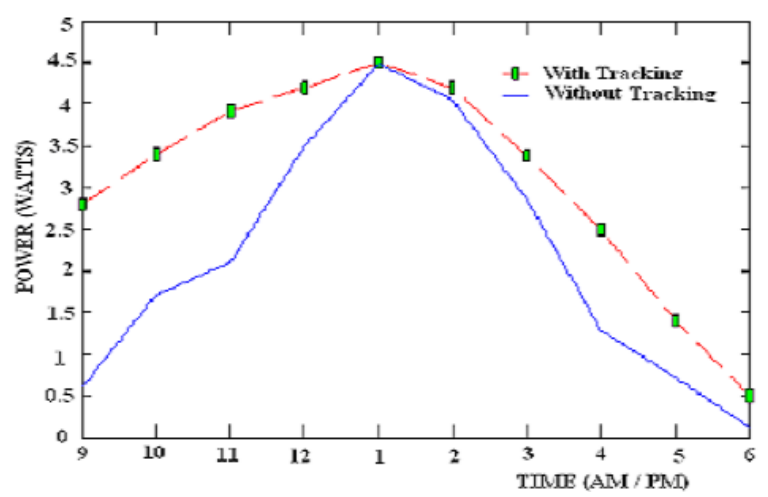

Fig.8. Efficiency Chart $[1,5,7,10,14,18,25,26]$

\section{Required Components for the Proposed System}

- Arduino mega 2560

- Jumpers wires

- $\quad$ Bearing model F204

- Bread board

- Battery

- LDRs (Light Dependent Resister)

- 5 Shafts

- $\quad$ 964R Servo motors

- Resisters

- Frame

- Polystyrene (for demo) painted solar panels [15, 18, 21]
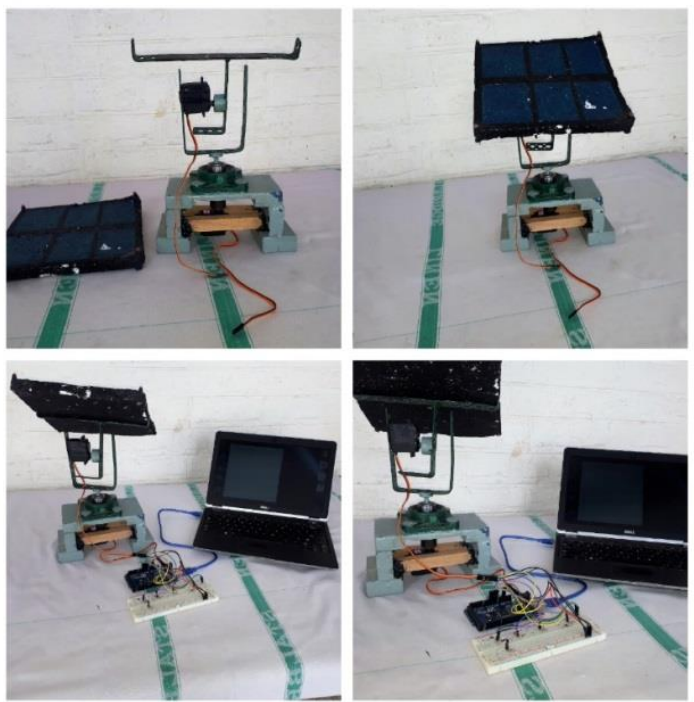

Fig.9. prototype Model for Testing 


\section{Comparision between Fixed and Dual Axis Tracker}

When the circuit and the programming code testing is begins of the solar tracking system on the bread board every and the each time of the testing in the incremental model error is occurred and then which error is removed in the next increment in the incremental model of removing that type error . when one error is removed then other error is occurred and which is removed in the next increment this process is goes to 6 increment and then error is removed and testing is successfully done and the errors is point out and discussed above is mentioned with solution in the below with the testing diagram on the bread board. The circuit and the resisters as well as the LDRs combination is tested so that the LDRs works properly in order to achieve the maximum efficiency of the solar track is about to $38 \%$ to $65 \%$.

In improving Efficiency a lot of errors occur and more than one hardware changes is made and many devices is burned during the circuit testing process. At last the test is completed and the efficiency of the solar tracked which is $65 \%$ or more is achieved. [7, 10, 15, 23, 24]

Table 3. Testing the Solar System [6, 20]

\begin{tabular}{|l|l|l|l|}
\hline Time & $\begin{array}{c}\text { Single } \\
\text { (AMP) }\end{array}$ & $\begin{array}{c}\text { Dual axis } \\
\text { (AMP) }\end{array}$ & $\begin{array}{c}\text { Proposed } \\
\text { Dual axis } \\
\text { (AMP) }\end{array}$ \\
\hline 08.00 AM & 52.50 & 106.25 & 110.12 \\
\hline 09.00 AM & 68.70 & 112.50 & 119.35 \\
\hline 10.00 AM & 93.17 & 115.00 & 135.30 \\
\hline 11.00 AM & 101.25 & 118.75 & 155.25 \\
\hline 12.00 PM & 115.00 & 123.75 & 165.22 \\
\hline $01.00 \mathrm{PM}$ & 118.18 & 123.75 & 172.25 \\
\hline $02.00 \mathrm{PM}$ & 110.00 & 123.75 & 183.20 \\
\hline $03.00 \mathrm{PM}$ & 95.00 & 122.55 & 209.14 \\
\hline $04.00 \mathrm{PM}$ & 52.50 & 118.75 & 185.15 \\
\hline $05.00 \mathrm{PM}$ & 28.75 & 118.75 & 147.58 \\
\hline $06.00 \mathrm{PM}$ & 10.00 & 90.00 & 104.65 \\
\hline Total & 846.25 & 1274.00 & 1687.21 \\
\hline
\end{tabular}

\section{Conclusion}

Fixed solar tracker works with the efficiency of $22 \%$ later on single axis solar tracking system is introduced which efficiency is about to $33-38 \%$.after that a dual axis solar tracker is introduced which efficiency is about $59 \%$.Now my contribution is to increase the efficiency of the solar tracker from $59 \%$ to the $65 \%$ with the codding algorithm and the additional use of the $5^{\text {th }}$ LDRs in frame, it is a big very big achievement.

\section{References}

[1] 1inali Wahane, 2. G. (2014). Solar Tracking System Using Artificial Intelligence. The International Journal Of Engineering And Science (Ijes), 32-37.

[2] Abdullah, M. (2018, 2 14). Solar Panel Installation Price Estimation. (Q. A. Haq, Interviewer)

[3] Aedb (Alternative Energy Development Board). (2018, 1 1). Solar-Power. Retrieved From Www.Aedb.Org: Http://Www.Aedb.Org/Ae-Technologies/Solar-Power

[4] Aedb (Alternative Energy Development Board). (2018, 1 5). Solar-Resources. Retrieved From Www.Aedb.Org: Http://Www.Aedb.Org/Ae-Technologies/Solar-Power/Solar-Resources

[5] Arsalan, S. (2013). Sun Tracking System With Microcontroller 8051. International Journal Of Scientific $\&$ Engineering Research (Ijser). 
[6] D. Venkatakrishna, E. S. (2015). Improved Structure Of Automatic Solar Tracking System. International Journal Of Engineering Sciences \& Research Technology (Ijesrt).

[7] Dipti Bawa, C. P. (2013). Fuzzy Control Based Solar Tracker Using Arduino Uno. International Journal Of Engineering And Innovative Technology (Ijeit).

[8] Electronics Maker (Em) Published By Em Media Llp. (2018, 1 12). Design-Of-Automatic-SolarTracking-Prototype. Retrieved From Www.Electronicsmaker.Com: $\mathrm{Http} / / /$ Electronicsmaker.Com/Design-Of-Automatic-Solar-Tracking-Prototype

[9] Electronicshub Administrator. (2018, 1 9). Arduino-Solar-Tracker. Retrieved From Www.Electronicshub.Org: Https://Www.Electronicshub.Org/Arduino-Solar-Tracker/

[10] Ghassoul, M. (2013). Design Of An Automatic Solar Tracking System To Maximize Energy Extraction. International Journal Of Emerging Technology And Advanced Engineering (Ijetae).

[11] Himanshu N. Puranik1, N. Q. (2016). Design And Implementation Of Sun Tracker Solar Panel With Smart Monitoring System. International Journal Of Advanced Research In Electrical,Electronics And Instrumentation Engineering.

[12] Inovix Labz@2013. (2018, 1 14). Solar-Tracking-System. Retrieved From Www.Sites.Google.Com: Https://Sites.Google.Com/Site/Innovativeelectrnx/Solar-Tracking-System

[13] International And Multidisciplinary Digital Publishing Institute. (2018, 1 14). 14248220/13/3/3157/Htm. Retrieved From Www.Mdpi.Com: Http:/Www.Mdpi.Com/1424$8220 / 13 / 3 / 3157 / \mathrm{Htm}$

[14] K P J Pradeep1, K. S. (2014). Development Of Dual-Axis Solar Tracking Using Arduino With Lab View. International Journal Of Engineering Trends And Technology (Ijett).

[15] K. Praveen Kumar Yadav1, M. S. (2016). Sun Tracking Solar Panel Using Arduino Time Control. International Journal Of Engineering Science And Computing (Ijesc).

[16] Ke Administrator. (2018, 1 4). Ec-Calculator. Retrieved From Www.Ke.Com.Pk: Http://Www.Ke.Com.Pk/Sustainability/Energy-Conservation/Ec-Calculator/

[17] Kitronik Ltd. (2018, 1 13). How-An-Ldr-Light-Dependent-Resistor-Works. Retrieved From Www.Kitronik.Co.Uk: Https://Www.Kitronik.Co.Uk/Blog/How-An-Ldr-Light-Dependent-ResistorWorks/

[18] Leela S.Bitla1, Y. M. (2016). Dual Axis Solar Trac King System For Maximum Power Using Arduino. Ijarse.

[19] Mr. Amjad Is Working As Chief Executive Officer Of Quaid-I-Azam Solar Power (Pvt) Ltd. (2018, 13 ). Solar-Power. Retrieved From Www.Qsolar.Com: Https://Www.Qasolar.Com/

[20] Mustafa, F. M. (2016). Dual-Axis Solar Tracking Over Fixed Solar. International Journal Of Advances In Engineering \& Technology(Ijaet), 563-568.

[21] Prof. Pooja K. Chhatwani\#1, P. J. (2013). Intelligent Solar Tracker System Implemented On 8051 Microcontroller. International Journal Of Engineering Trends And Technology (Ijett).

[22] Sachin Sahu1, S. P. (2017). A Review On Solar Tracking System. International Journal For Technical Education And Research Innovations (Ijteri).

[23] Sirigauri N, R. S. (2015). Design And Implementation Of Dual Axis Solar Tracking System. International Journal Of Engineering Research And Applications.

[24] Srijesh Chettri, A. C. (2016). Dual Axis Self-Tracking Solar Panel. International Journal Of Computer Applications (Ijca).

[25] Sudip Das, B. P. (2016). Design \& Development Of Dual Axis Solar Tracking System To Get Optimum Power. International Journal Of Innovations In Engineering And Technology (Ijiet).

[26] Suman Ghosh1, S. R. (2016). Designing A Dual-Axis Solar Tracking System. International Journal Of Advanced Research In Electrical,Electronics And Instrumentation Engineering.

[27] Liping Dong1,Zhen AN2,Lina Hao3, 2015. 


\section{Authors' Profile}

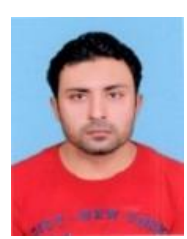

Qamar atta ul haq was born on Nov 9, 1993 in Multan .He completed his Higher Secondary School and college from the hometown Multan. He completed his graduation degree from the Institute of Southern Punjab Multan Pakistan and then he completed his master degree from ISP Multan and got Gold medal for his work. After that he goes to the IUB University for MSCS with the specialization in Artificial Intelligence and carry on his research to facilitate the Nation from his research and work.

How to cite this paper: Qamar Atta Ul Haq,"Design and Implementation of Solar Tracker to Defeat Energy Crisis in Pakistan", International Journal of Engineering and Manufacturing(IJEM), Vol.9, No.2, pp.31-42, 2019.DOI: $10.5815 / \mathrm{ijem} .2019 .02 .03$ 